\title{
Branch retinal artery occlusion associated with posterior uveitis
}

\author{
Rim Kahloun 1,2, Samah Mbarek ${ }^{1,2}$, Imen Khairallah-Ksiaa ${ }^{1,2}$, Bechir Jelliti ${ }^{1,2}$, Salim Ben Yahia ${ }^{1,2}$ \\ and Moncef Khairallah ${ }^{1,2^{*}}$
}

\begin{abstract}
Background: The purpose of this study is to report the clinical features and visual outcome of branch retinal artery occlusion (BRAO) associated with posterior uveitis. This is a retrospective study including the 18 eyes of 18 patients. All patients underwent a complete ophthalmic evaluation. Fundus photography, fluorescein angiography, and visual field testing were performed in all cases.
\end{abstract}

Results: Diseases associated with BRAO included active ocular toxoplasmosis in 7 patients, rickettsiosis in 4, Behçet's uveitis in 2, West Nile virus infection in 1, idiopathic retinal vasculitis in 1, Crohn's disease in 1, ocular tuberculosis in 1 , and idiopathic retinal vasculitis, aneurysms, and neuroretinitis syndrome in 1 patient. The mean initial visual acuity was 20/50. BRAO involved the first order retinal artery in 33.3\% of the eyes, the second order retinal artery in $33.3 \%$, an arteriole in $27.8 \%$, and a cilioretinal artery in 5.5\%. The macula was involved in $44.4 \%$ of the eyes and an acute focus of retinitis or retinochoroiditis was associated to BRAO in $55.5 \%$. Repermeabilization of the occluded artery occurred in all patients with permanent scotomas in the corresponding visual field. The mean visual acuity at last visit was 20/32.

Conclusions: BRAO, with subsequent visual impairment, may occur in the eyes with posterior uveitis. Physicians should be aware of such vision-threatening complication of infectious and inflammatory eye diseases.

Keywords: Branch retinal artery occlusion, Posterior uveitis, Fluorescein angiography, Visual impairment

\section{Background}

Infectious or inflammatory eye diseases may result in numerous vascular complications. These mainly include retinal hemorrhages, retinal vascular hyperpermeability, retinal vascular occlusion, macroaneurysms, retinal or choroidal neovascularization, and retinochoroidal anastomosis [1,2]. Although branch retinal vein occlusion (BRVO) is considered to be a common complication of posterior uveitis associated with retinal vasculitis, data on the inflammatory branch retinal artery occlusion (BRAO) are relatively scarce. In this study we describe the clinical features and visual outcome of BRAO associated with posterior uveitis.

\footnotetext{
* Correspondence: moncef.khairallah@rns.tn

'Department of Ophthalmology, Fattouma Bourguiba University Hospital, Monastir 5019, Tunisia

${ }^{2}$ Faculty of Medicine, University of Monastir, Monastir 5019, Tunisia
}

\section{Results}

Ten patients (55.5\%) were men, and eight patients $(44.5 \%)$ were women. The age of our patients ranged from 18 to 56 years (mean 37.8; median 37.5).

Diseases associated with BRAO were active ocular toxoplasmosis in 7 patients $(7.5 \%$ of all toxoplasmosis cases recorded in our department) (Figure 1), rickettsiosis (Mediterranean spotted fever) in 4 patients $(4.2 \%$ of all Mediterranean spotted fever cases recorded in our department) (Figure 2), Behçet's uveitis in 2 patients (1.3\% of all Behçet's uveitis cases recorded in our department), West Nile virus infection in 1 patient (2.4\% of all cases of West Nile virus infection with posterior uveitis recorded in our department), idiopathic retinal vasculitis in 1 patient, Crohn's disease in 1 patient, ocular tuberculosis in 1 patient (4\% of all ocular tuberculosis cases recorded in our department) and idiopathic retinal vasculitis, aneurysms, and neuroretinitis (IRVAN) syndrome in 1 patient (Table 1). 

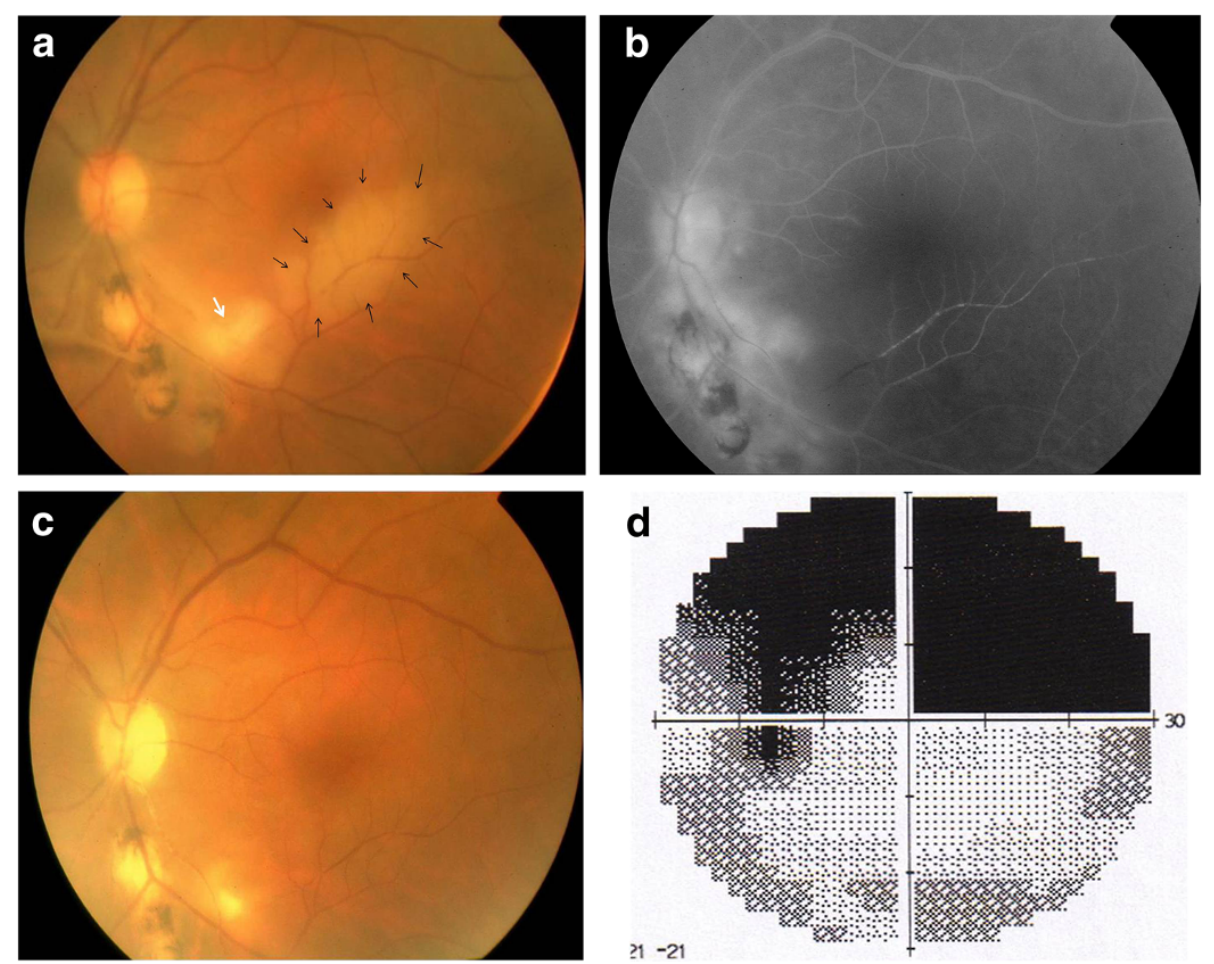

Figure 1 Branch retinal artery occlusion associated with ocular toxoplasmosis. (a) Color fundus photograph of the left eye of a patient with ocular toxoplasmosis shows an active focus of retinochorioretinitis (white arrow) adjacent to old pigmented scars infero-temporally and an area of retinal whitening along the inferior temporal arcade (black arrows). (b) Early phase fluorescein angiogram shows delayed filling of inferior temporal branch retinal artery, capillary nonperfusion corresponding to the area of retinal whitening, and hypofluorescence of the focus of retinochoroiditis. (c) Color fundus photograph 3 months later shows resolution of the retinal whitening. Note the presence of a persistent scotoma on automated perimetry (d).

Initial visual acuity (VA) ranged from $20 / 400$ to $20 / 20$ (mean, 20/50; median, 20/40). Fundus examination showed the focal area of retinal whitening corresponding to the occluded artery in all cases. An acute focus of retinitis or retinochoroiditis was associated to BRAO in 10 eyes (55.5\%), including 7 eyes with ocular toxoplasmosis, 2 eyes with rickettsiosis, and 1 eye with Behçet's uveitis. The occluded vessel passed through the area of acute retinitis or retinochoroiditis in all these cases.

Fluorescein angiography (FA) revealed delayed filling of the occluded branch retinal artery and capillary nonperfusion corresponding to the area of retinal whitening seen clinically in all cases.

BRAO involved a first order retinal artery in 6 eyes (33.3\%), a second order retinal artery in 6 eyes (33.3\%), an arteriole in 5 eyes $(27.8 \%)$ and a cilioretinal artery in 1 eye (5.5\%). The macula was involved in 8 eyes (44.4\%).

A cilioretinal artery occlusion associated with BRVO was recorded in one patient with Behçet's uveitis. A BRAO associated with BRVO was recorded in one eye with tuberculous uveitis. In the eye with IRVAN syndrome, BRAO occurred at the level of an aneurysm and was not associated to any prior laser photocoagulation (Figure 3). Optical coherence tomography (OCT) showed serous retinal detachment in 4 of the 8 eyes (50\%).

Patients with ocular toxoplasmosis were treated with a combination of pyrimethamine $(100 \mathrm{mg}$ the first day then $50 \mathrm{mg}$ daily), azithromycin (500 $\mathrm{mg}$ the first day then $250 \mathrm{mg}$ daily), and prednisone for 4 to 6 weeks. Patients with rickettsiosis were treated with a 2 -week course of oral doxycycline. Patients with Behçet's uveitis were treated with systemic corticosteroids associated with immunosuppressive therapy (azathioprine for the first patient and a combination of azathioprine and cyclosporine for the second patient). Patient with ocular tuberculosis was treated with antituberculous therapy (four drugs for 2 months followed by two drugs for 7 months) associated with oral corticosteroids. Patients with idiopathic retinal vasculitis, Crohn's disease, and IRVAN syndrome were treated with oral corticosteroids.

During follow-up, all foci of retinitis or retinochoroiditis became inactive. Repermeabilization of the occluded artery occurred in all patients with residual scotoma in the corresponding visual field (Figure 1). Retinal 

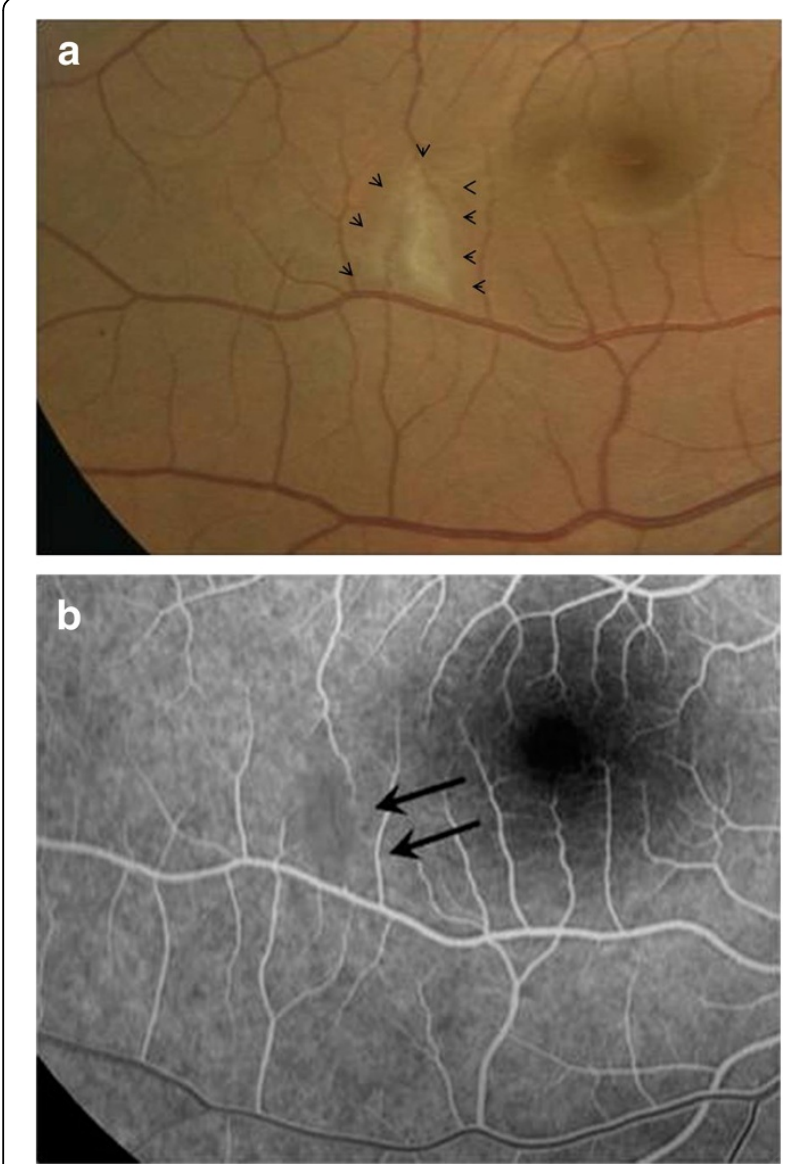

Figure 2 Branch retinal artery occlusion associated with rickettsiosis. (a) Color fundus photograph of the right eye of a patient with rickettsiosis shows an area of retinal whitening sparing the fovea (arrow heads). (b) Early phase fluorescein angiogram confirms the diagnosis of branch retinal arteriolar occlusion sparing the fovea (black arrows).

neovascularisation was recorded in one eye (patient with West Nile virus infection). VA at last visit ranged from 20/200 to 20/20 (mean, 20/32; median, 20/25).

\section{Discussion}

Most publications on inflammatory BRAO consisted of single-case reports, and to our knowledge, our study is the largest case series reported to date. Our findings, consistent with those from previous reports, show that ocular toxoplasmosis is the leading cause of inflammatory BRAO [3-10], followed by an array of other inflammatory infectious or noninfectious retinochoroidal disorders [11-22]. Rickettsial infection was found to be the second most common cause of BRAO in our series. Mediterranean spotted fever, a rickettsial disease caused by Rickettsia conorii, is endemic in the Mediterranean region including North Africa [11]. Retinal vascular involvement in this disease is common due to a marked tropism of the rickettsial organisms in the small blood vessels throughout the body, including the retina [11]. Cat scratch disease, an infectious disease caused by the gram-negative bacteria Bartonella henselae that has a similar tropism in the retinal vessels has been previously associated with BRAO [12-15]. No case of BRAO due to cat scratch disease has been recorded in our series of examinations.

Behçet's disease is a leading cause of uveitis along the Old Silk Road, including North African countries [23]. Behçet's uveitis typically presents in the form of panuveitis associated with retinal periphlebitis that may be complicated with BRVO [23]. However, retinal artery involvement

\section{Table 1 Demographic and clinical characteristics of our patients}

\begin{tabular}{|c|c|}
\hline Characteristics & Values \\
\hline Number of patients (eyes) & $18(18)$ \\
\hline \multicolumn{2}{|l|}{ Age (years) } \\
\hline Range & $18-56$ \\
\hline Mean & 37.8 \\
\hline Median & 37.5 \\
\hline \multicolumn{2}{|l|}{ Gender $(n)(\%)$} \\
\hline Male & $10(55.5)$ \\
\hline Female & $8(44.5)$ \\
\hline \multicolumn{2}{|c|}{ Associated inflammatory eye disease (n) (\%) } \\
\hline Ocular toxoplasmosis & $7(38.9)$ \\
\hline Rickettsiosis & $4(22.2)$ \\
\hline Behçet's disease & $2(11.1)$ \\
\hline Ocular tuberculosis & $1(5.5)$ \\
\hline IRVAN syndrome & $1(5.5)$ \\
\hline Crohn disease & $1(5.5)$ \\
\hline Idiopathic vasculitis & $1(5.5)$ \\
\hline West Nile virus infection & $1(5.5)$ \\
\hline Cat scratch disease & $0(0)$ \\
\hline \multicolumn{2}{|l|}{ Site of occlusion (n) (\%) } \\
\hline First order retinal artery & $6(33.3)$ \\
\hline Second order retinal artery & $6(33.3)$ \\
\hline Arteriole & $5(27.8)$ \\
\hline Cilioretinal artery & $1(5.5)$ \\
\hline \multicolumn{2}{|l|}{ Initial visual acuity } \\
\hline Range & $20 / 400-20 / 20$ \\
\hline Mean & $20 / 50$ \\
\hline Median & $20 / 40$ \\
\hline \multicolumn{2}{|l|}{ Visual acuity at last visit } \\
\hline Range & $20 / 200-20 / 20$ \\
\hline Mean & $20 / 32$ \\
\hline Median & $20 / 25$ \\
\hline
\end{tabular}

IRVAN, idiopathic retinal vasculitis, aneurysms, and neuroretinitis syndrome. 

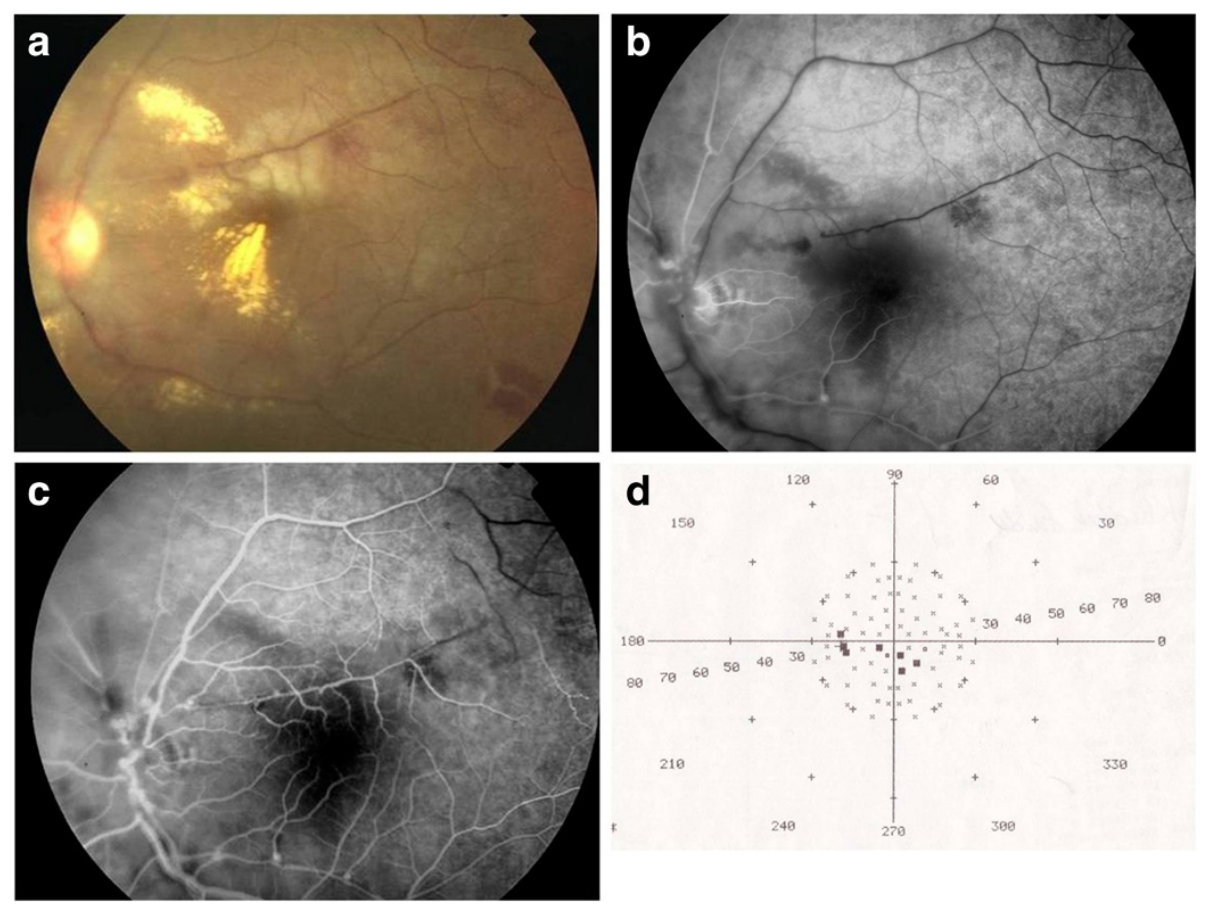

Figure 3 Branch retinal artery occlusion associated with IRVAN syndrome. (a) Color fundus photograph of the left eye of a patient with IRVAN syndrome shows an area of retinal whitening along upper temporal vessel. Early phase (b) and mid-phase (c) fluorescein angiograms show branch retinal artery occlusion. Note the presence of multiple macroaneurysms on the course of this artery. (d) Visual field testing shows multiple central scotomas in the area corresponding to the occluded artery.

causing BRAO can also occur in the setting of Behçet's uveitis [16].

Inflammatory BRAO usually results in visual field defect without or with impairment of VA. The diagnosis of BRAO primarily relies on clinical examination, but related clinical features might be overlooked or misdiagnosed as signs of retinochoroidal inflammation. FA is very useful in establishing a definitive diagnosis of inflammatory BRAO, particularly in subclinical cases or those with a challenging diagnosis.

Several mechanisms might be involved in the development of BRAO associated with posterior uveitis. BRAO may occur at the site of an active focus of retinitis or retinochoroiditis. It could result from a direct compression of the artery by the focus of retinitis or chorioretinitis, leading to interruption of the blood flow. Arterial occlusion near active inflammatory foci may also be explained by arteriolar contraction associated with increased blood viscosity and inhibition of coagulation due to heparin release from the mast cells as a response to an acute inflammatory stimulus [5].

In the absence of the focus of retinitis or chorioretinitis, BRAO could be due to perivasculitis resulting from the infiltration of the vessel wall by the inflammatory cells, which may cause its thickening and as the consequence, disruption of blood flow and arterial thrombosis [14].
In patients with IRVAN syndrome, BRAO have been reported following laser photocoagulation of the aneurysms $[19,20]$. To the best of our knowledge, only one case of IRVAN syndrome complicated with a primary BRAO similar to our case has been previously reported [21]. The location of macroaneurysm at the junction of the retinal artery tree might make it prone to spontaneous thrombosis.

The cilioretinal artery occlusion in our patient with Behçet's uveitis probably was functional in nature. An increase of the intraluminal pressure in the retinal capillaries due to the BRVO which is exceeding the pressure in the cilioretinal artery could lead to its occlusion [16].

Resolution of the ocular inflammation and reperfusion of the occluded artery occurred in all patients following anti-infectious and/or systemic corticosteroid therapy. Improvement of VA was recorded in all patients; however, the retinal function did not fully recover in cases with BRAO involving the macula with persistent field defects probably due to the atrophy of the retinal neuroepithelium or macular ischemia. Early and appropriate treatment with anti-inflammatory and/or anti-infectious medication may help induce prompt resolution of the ocular inflammation and reperfusion of the occluded artery and improve visual outcome. 


\section{Conclusions}

In conclusion, BRAO may occur in association with an array of infectious or non-infectious posterior uveitis entities, dominated by toxoplasmic retinochoroiditis. It usually causes visual field defect without or with VA impairment. A careful clinical examination, complemented with FA, is mandatory in order not to miss a diagnosis of inflammatory BRAO. The role of medical treatment on the course of the occlusive event requires further investigation.

\section{Methods}

This is a retrospective study including 18 eyes of 18 patients with BRAO associated with posterior uveitis. All patients were examined at the Department of Ophthalmology, Fattouma Bourguiba University Hospital, Monastir, Tunisia between 1998 and 2011. The study was approved by the ethics committee of our institution.

The patients underwent a complete ophthalmic evaluation that included measurement of best-corrected VA, slit-lamp examination, and dilated fundus examination. Fundus photography, FA, and visual field testing were performed in all cases. OCT was performed in eight patients. Mean follow-up was 10 months (range, 6 to 24 months).

\section{Competing interest}

The authors declare that they have no competing interests.

\section{Authors' contributions}

RK, SM, IK, BJ, SBY, and MK, participated in the sequence alignment and in the design of the study, performed the statistical analysis, and drafted the manuscript. RK and MK conceived of the study and participated in its design and coordination. All authors read and approved the final manuscript.

Received: 11 September 2012 Accepted: 12 September 2012

Published: 21 January 2013

\section{References}

1. Brézin AP (2012) Uveitis. Presse Med 41:10-20

2. Yamanaka E, Ohguro N, Kubota A, Yamamoto S, Nakagawa Y, Tano Y (2004) Features of retinal arterial macroaneurysms in patients with uveitis. $\mathrm{Br} J$ Ophthalmol 88:884-886

3. Morgan CM, Gragoudas ES (1987) Branch retinal artery occlusion associated with recurrent toxoplasmic retinochoroiditis. Arch Ophthalmol 105:130-131

4. Haefliger E, Müller O (1980) Branch artery occlusion due to focal necrotizing retinitis probably caused by toxoplasmosis. Klin Monbl Augenheilkd 176:613-618

5. Braunstein RA, Gass JDM (1980) Branch artery obstruction caused by toxoplasmosis. Arch Ophthalmol 98:512-513

6. Pakalin S, Arnaud B (1990) Arterial occlusion associated with toxoplasmic chorioretinitis. J Fr Ophtalmol 13:554-556

7. Williamson TH, Meyer PA (1991) Branch retinal artery occlusion in Toxoplasma retinochoroiditis. Br J Ophthalmol 75:253

8. Gentile RC, Berinstein DM, Oppenheim R, Walsh JB (1997) Retinal vascular occlusions complicating acute toxoplasmic retinochoroiditis. Can J Ophthalmol 32:354-358

9. Küçükerdönmez C, Yilmaz G, Akova YA (2004) Branch retinal arterial occlusion associated with toxoplasmic chorioretinitis. Ocul Immunol Inflamm 12:227-231

10. Miserocchi E, Modorati G, Rama P (2009) Atypical toxoplasmosis masquerading late occurrence of typical findings. Eur J Ophthalmol 19:1091-1093
11. Khairallah M, Ladjimi A, Chakroun M, Messaoud R, Ben Yahia S, Zaouali S, Ben Romdhane F, Bouzouaia N (2004) Posterior segment manifestations of Rickettsia conorii infection. Ophthalmology 111:529-534

12. Gray AV, Reed JB, Wendel RT, Morse LS (1999) Bartonella henselae infection associated with peripapillary angioma, branch retinal artery occlusion, and severe vision loss. Am J Ophthalmol 127:223-224

13. Cohen SM, Davis JL, Gass DM (1995) Branch retinal arterial occlusions in multifocal retinitis with optic nerve edema. Arch Ophthalmol 113:1271-1276

14. Ormerod LD, Skolnick KA, Menosky MM, Pavan PR, Pon DM (1998) Retinal and choroidal manifestations of cat-scratch disease. Ophthalmology 105:1024-1031

15. Solley WA, Martin DF, Newman NJ, King R, Callanan DG, Zacchei T, Wallace RT, Parks DJ, Bridges W, Sternberg P Jr (1999) Cat scratch disease: posterior segment manifestations. Ophthalmology 106:1546-1553

16. Ben Yahia S, Kahloun R, Jelliti B, Khairallah M (2011) Branch retinal artery occlusion associated with Behçet disease. Ocul Immunol Inflamm 19:293-295

17. Yokoi M, Kase M (2004) Retinal vasculitis due to secondary syphilis. Jpn J Ophthalmol 48:65-67

18. Khairallah M, Ben Yahia S, Attia S, Jelliti B, Zaouali S, Ladjimi A (2006) Severe ischemic maculopathy in a patient with West Nile virus infection. Ophthalmic Surg Lasers Imaging 37:240-242

19. Chang TS, Aylward GW, Davis JL, Mieler WF, Oliver GL, Maberley AL, Gass JD (1995) Idiopathic retinal vasculitis, aneurysms, and neuro-retinitis. Retinal vasculitis study. Ophthalmology 102:1089-1097

20. Terrada C, Dethorey G, Ducos G, Lehoang P, Bodaghi B, Souied EH (2011) Spontaneous branch artery occlusion in idiopathic retinitis, vasculitis, aneurysms, and neuroretinitis syndrome despite panretinal laser photocoagulation of widespread retina nonperfusion. Acta Ophthalmol 89:e542-e543

21. Venkatesh P, Verghese M, Davde M, Garg S (2006) Primary vascular occlusion in IRVAN (idiopathic retinal vasculitis, aneurysms, neuroretinitis) syndrome. Ocul Immunol Inflamm 14:195-196

22. Zamora RL, del Priore LV, Storch GA, Gelb LD, Sharp J (1996) Multiple recurrent branch retinal artery occlusions associated with Varicella zoster virus. Retina 16:399-404

23. Tugal-Tutkun I (2009) Behçet's uveitis. Middle East Afr J Ophthalmol 16:219-224

doi:10.1186/1869-5760-3-16

Cite this article as: Kahloun et al:: Branch retinal artery occlusion associated with posterior uveitis. Journal of Opthalmic Inflammation and Infection 2013 3:16.

\section{Submit your manuscript to a SpringerOpen ${ }^{\odot}$ journal and benefit from:}

- Convenient online submission

- Rigorous peer review

- Immediate publication on acceptance

- Open access: articles freely available online

- High visibility within the field

- Retaining the copyright to your article

Submit your next manuscript at $>$ springeropen.com 